\title{
Zombies and Ethical Theories: Exploring Transformational Play as a Framework for Teaching with Videogames
}

\author{
Filipa de Sousa*, Ingvill Rasmussen, Palmyre Pierroux \\ Department of Education, University of Oslo, P.O. Box 1092 Blindern, 0317 Oslo, \\ Norway
}

\begin{abstract}
Videogames are included among the wide array of digital resources available to teachers to foster student engagement and teach domain-specific content. In this study, we analyze how two teachers in two countries used the commercial videogame The Walking Dead ${ }^{\mathrm{TM}}$ to teach ethical theories in upper secondary citizenship education. In both cases, students collaborated in playing the videogame, and teachers led whole-class and small-group discussions to relate the game narrative to the curriculum. However, the analysis identified two different instructional designs and dialogic approaches to integrating the videogame with other educational resources. Extending the concept of transformational play, the analysis showed how the respective teaching approaches supported student learning and engagement by facilitating different types of positioning work.
\end{abstract}

Keywords: Game-based learning; Transformational play; Dialogical teaching and learning; Classroom interaction; Citizenship education and ethics

\section{Introduction}

Young people worldwide play commercial videogames, and in many countries, teachers are exploring the use of videogames to foster student learning. In this paper, we analyze how two teachers, one from Norway and one from Portugal, used the same commercial videogame to teach ethics in citizenship education at the upper secondary level. The teachers designed similar activities for the curriculum, which involved collaboratively playing the videogame in class. Both teachers paused the game at decisive narrative moments and led discussions of moral dilemmas in relation to ethical theories in the curriculum. The questions raised in this study are based on an overall interest in exploring how teachers plan and enact the use of commercial videogames, and digital technologies more broadly, as resources for learning in formal education. Videogames have a special status as a digital learning resource because they offer new types of "worlds" in which players experience the consequences of their actions in the unfolding of a story or the solving of a quest, challenge or problem, as these are displayed on a screen (Barab, Gresalfi, \& Arici, 2009). Researchers also point to videogames as powerful learning resources for promoting digital literacy and other twenty-first century skills because adolescents identify with this resource (Erstad, 2013; Gee, 2003; Hull \& Schultz, 2001).

Yet much has been written about whether commercial games can be productively used in formal education (e.g., de Freitas, 2006; Linderoth, 2012; Selwyn, 2016). Concerns have been raised that commercial videogames are not good 
learning environments because they are designed for entertainment rather than for learning in formal education, and many of them present violent content (Linderoth, 2012). Instead, serious games should be used in school (Marino \& Hayes, 2012), as they are designed for learning in a specific knowledge domain, integrating curricular content while maintaining the engagement aspects of gameplay (Sanchez, 2013). Serious games, if properly designed, provide educationally relevant and problem-rich environments, tools, and experiences that ensure learners will develop rich content understandings (Barab, Gresalfi, \& Ingram-Goble, 2010).

In this paper, we explore the premise put forth in the research that in addition to being entertaining, commercial videogames often have designs that are based on educational principles that foster cognitive and social skills (e.g., Squire, 2005). Videogames can, for example, involve students in adopting different perspectives through role-play that invites them to assume different identities in the game. Gee (2003) posits a tripartite play of identities: a virtual identity (the character), a projective identity (how the values of the player are projected in the character) and multiple real-world socio-cultural identities (who the player is in real life and who she intends to become). This approach has been influential in empirical studies showing how players' ethical understandings develop as they explore new identities in gameplay (Edmiston, 2008). In the virtual identity, the learner makes, and is accountable for, choices with underlying values and goals that have been preprogrammed, and the projective identity must navigate the relationship between the different identities. Furthermore, immersion in a story or a game character may lead to learning the story's "moral" (Baranowski et al., 2008; Ryan, Rigby, \& Przybylski, 2006).

Regardless of the stance on whether serious or commercial games are appropriate for formal education, there is general consensus that the teacher's role is central in promoting discussions that invite questioning and multiple viewpoints, engaging students in making justifications that are relevant to learning by relating domain-specific content to the gameplay (Arici, 2008; Barab et al., 2012; Barab et al., 2010; Gresalfi \& Barab, 2011; Hanghøj, 2013). However, teachers' learning aims for gameplay are not always made explicit for students (Squire, 2005). A meta-analysis found that serious games are more effective when integrated with teacher-led discussions that prompted students to verbalize knowledge and make connections to previous knowledge (Wouters et al., 2013). This finding is also emphasized in the literature on simulations (e.g. Kriz, 2010). Within this field, studies have provided insights into how simulators may serve as productive environments for training professional action, and how such environments also provide teachers opportunities to connect student assessments more directly to these enactments (Selberg \& Lundin, 2017). Another central finding is that the teacher's role and instructional design for' briefing and debriefing' simulator lessons is key to the effectiveness of simulators as learning environments (Hontvedt, 2015). This finding aligns with a number of empirical studies showing that teachers' class dialogues are particularly important to learning from games (serious or commercial), as connections to domain-specific content must be made explicit: "In play, the consequences of actions and learning 
only have relevance within the confines of the game" (Jahreie et al., 2011, p. 238). In other words, support and progression might be incorporated into the game design, but empirical findings stress that students depend on their teachers to make links between the game and curricular content (Hanghøj \& Brund, 2010; Silseth 2012). Students need instructional assistance to understand knowledge representations that may be tacitly embedded in games, textbooks, and other resources (Gilje et al. 2016; Rasmussen \& Ludvigsen, 2010). In sum, extensive research shows that the intended, often advanced designs of digital learning resources like serious games and simulations does not assure that learning takes place. Rather, the productive use of digital technology, including commercial videogames in formal learning settings, also relies on how the resource is integrated into the teacher's enacted design - where teacher's dialogic interactions with students is a key issue (Ramussen \& Ludvigsen, 2010; Mercer \& Howe, 2012).

To study teachers' use of videogames as resources for learning in classroom settings, we draw on an analytical framework that explicitly addresses the learning potential in game-based learning (GBL). This framework is called transformational play (TP), and was developed for the learning designs of serious games (Barab et al., 2010). We adapt this framework in an empirical investigation of how two upper secondary school teachers integrated a commercial videogame with other educational resources in lessons on ethical theories, with a particular focus on the teachers' dialogic interactions and enacted learning designs.

\section{Analytical Framework: A Dialogic Approach to Transformational Play}

There are three key principles that characterize transformational play (TP). First, roleplaying facilitates the positioning of persons with intentionality (Barab et al., 2010) in ways that support critical reflection and the experience of multiple perspectives; players perceive themselves as protagonists who have the responsibility to make choices that will impact the game's story. Second, TP encourages players to use theoretical content to solve problems in the game's setting. Barab et al. (2010) described this as positioning content with legitimacy. In designs for GBL, subject content and conceptual understanding are positioned as situated knowledge. This means they are used within the game's setting as legitimate and valid resources for solving problematic situations as they unfold. Positioning content in this way transforms students' understanding because they become aware of concrete practical applications and broader meanings across contexts. The third aspect of TP is positioning context with consequentiality (Barab et al., 2010). Game environments depend on players' actions, allowing the players to judge the consequences of their actions as the story unfolds in response to their decisions. In designing for TP, game elements must be combined in ways that create consequential learning spaces for the player to act as a protagonist and to apply theoretical content to solve problems as they arise. Together, the narrative, role-playing, content, and interactive design elements create a context in which players' choices have meaning and consequence (Barab et al., 2012). TP may thus be described as a normative framework for thinking about the design of serious games and curricular units, identifying aspects that can 
contribute to learning when designing educational games (Barab et al., 2010). We extend TP principles to the study of commercial videogames as learning resources in teachers' instructional designs, by employing the concepts of positioning person, content, and context in the analysis of dialogic interactions in two different classrooms.

Our focus on dialogue entails investigating the ways the teachers facilitate transformational play while dialogically promoting participation and discussion among students (Mercer \& Howe, 2012). Building on sociocultural approaches and activity theory, TP underlies the idea that learning in videogames involves active participation (Barab et al., 2010). Reasoning and knowing are seen as distributed acts that exist in the flow of activities as people interact with others and with social, physical, and knowledge resources. Dialogical approaches entail listening, reformulating, challenging points of view, and collaboratively building arguments from group discussions (Wegerif, 2011). Dialogue promotes what Bakhtin (1981) called the inter-animation of different voices that allows meanings to emerge and develop through talk. Wegerif (2007) points to the benefits of opening dialogic spaces to deepen and broaden reflection when learning with technology, and seems especially important when using games or simulations as educational resources.

\subsection{Meaning making in citizenship education}

Dialogical teaching approaches are particularly relevant for citizenship education. Studies indicate the need to support students in both mastering ethical theory concepts and using them to reason about various moral issues that can entail emotional or personal involvement. In a study of the teacher's role in promoting active enrolment in classroom conversations about moral issues, Willems et al. (2013) qualitatively compared teachers' conversations in four classroom settings and found that of primary importance were (a) leading students to be morally reasonable, (b) stimulating their emotional involvement, and (c) guiding them toward a normative ideal of virtue. These aspects of moral reasoning are also relevant in the curriculum and teaching approaches studied in this paper.

A model of dialogical teaching, according to Alexander (2006), entails a sequence of talk in which (a) the teacher poses questions that are framed to elicit reflection; (b) answers point to new questions in a reflexive chain; and (c) the teacher supports students' learning by weaving their contributions into a coherent whole. In studies of teacher-led discourse in classroom settings, Mercer described productive interactions as, "co-reasoning, in which speakers share relevant knowledge, challenge ideas, evaluate evidence, consider options, and try to reach agreement in an equitable manner" (2008, p. 95). However, in citizenship education, it has been noted that teacher-led interventions to achieve agreement might not be the most useful dialogical strategy in this subject area, because moral and citizenship education are domains where a plurality of perspectives and opinions are highly valued (Schuitema et al., 2011); the quality of students' reasoning in class was key to their later ability to justify viewpoints on moral issues. Wertsch (1998) embraced this nuance in his notion of meaning making, which makes the subtle distinction between the mastery of factual 
or conceptual information and the personal appropriation of knowledge in learning processes, through which understanding is made "one's own." We draw on this nuance in our analysis of how teachers dialogically support student learning in ethics and citizenship education using a popular commercial videogame. Given the central role of dialogic interaction when learning with videogames, then, we focus on how dialogue between teacher and students is structured and related to the game's narrative structure and content. These have been noted as the distinguishing features of videogames compared to other digital resources used in classrooms (Barab, Gresalfi, \& Arici, 2009). The following research questions are addressed:

- How was the commercial videogame integrated with other educational resources by the teachers in the two classrooms?

- What kind of positioning work, key to transformational play, was accomplished through the teachers' dialogic interactions and the enacted learning designs?

- In which ways did the teachers' dialogic interactions support meaning making in citizenship education and ethics?

The inclusion of two different cases from two different countries is interesting given that the use and popularity of videogames are global. The aim is neither to perform a comparative study nor to identify national trends or tendencies, but rather to contribute to international research on the potential of GBL to foster adolescents' engagement in and dialogue about curriculum content. Studying two teachers' approaches to GBL allowed a richer analysis of such dialogic interactions.

\section{Method}

\subsection{The Videogame: The Walking Dead ${ }^{\mathrm{TM}}$}

The Walking Dead ${ }^{\mathrm{TM}}$ is a popular commercial role-playing videogame, where players control a male convicted murderer who is 'on the run' from the authorities and has taken responsibility for a little girl. Together, they travel through a zombie apocalypse scenario. To survive, players must make difficult choices. The game was not created for educational purposes, but the teachers viewed it as interesting for teaching ethics because the content presents difficult moral dilemmas and the player's agency impacts the story's narrative. The Walking Dead ${ }^{\mathrm{TM}}$ is used worldwide and contains universal dilemmas (e.g., to lie or not to lie), further reinforcing the value of studying this activity across countries. The teachers complemented the videogame with other game-like apps (Geddit ${ }^{\mathrm{TM}}$ and Kahoot $^{\mathrm{TM}}$ ) to collect students' opinions and votes at key moments.

\subsection{Domain-Specific Content: Citizenship Education and Ethical Theories}

A disciplinary focus on citizenship practice as 'active and critical engagement' (Haydn, 2012) is found in curriculum guidelines for citizenship education in different countries (Advisory Group on Citizenship 1998). In Norway, we followed a class in the subject "Knowledge of Christianity, Religion, Philosophies of Life and Ethics." 
This subject uses philosophical models as tools for analyzing and reflecting on ethical challenges (Norwegian Ministry of Education, 2015). In Portugal, we followed a subject called "Integration Area," which points to the integration of knowledge from several disciplinary fields (Portuguese Ministry of Education, 2004). In both countries, we followed classes during a curricular unit on ethical theories. Classification systems of ethical theories differ (Vestøl, 2004), as did the curricular content covered by teachers in the two countries. In Portugal, the ethical theories covered were utilitarianism, choosing the action that is useful to the greatest number of people; psychological egoism, acting in one's own individual interests; and deontology (also called duty ethics), the duty of acting according to universal good will toward others. In Norway, the teacher presented the following theories: virtue ethics, the moral action is whatever a virtuous person would do under the circumstances; closeness ethics, considering the proximity of the object (e.g., saving a relative instead of a stranger); and utilitarianism and duty ethics. As mentioned, the two teachers designed similar activities for the curriculum, which involved collaboratively playing the videogame in class, pausing, and discussing decisive moments to make moral decisions based on ethical theories for further action.

\subsection{Contexts}

The Norwegian class included 26 students (20 boys and six girls, 17-19 years old) in their third year at a regular upper secondary school. The teacher, a man in his late 20s, commonly used technology in his classes and designed the GBL practice that we studied. The students had previous experience with GBL because their school encouraged such pedagogical methods. In Portugal, we followed a smaller class (five boys and nine girls, 18-22 years old) in their second year of a vocational upper secondary program. The higher age of the students might be explained by difficult school trajectories, including lack of motivation, absenteeism, disciplinary problems, and poor grades. The teacher, a woman in her late 40s, was not accustomed to technology-enhanced teaching practices but decided to participate in the study because she believed GBL could help combat students' motivational problems. The participating students had no prior experience with GBL. In the Norwegian case, the activity took place in a regular classroom equipped with all the necessary ICT equipment, while in the Portuguese school the class moved to the school's ICT room to allow one-to-one access to computers.

\subsection{Data and Analytic Approach}

Data collection in both schools started with the curricular unit and covered the first five 'dilemmas' presented in the videogame. The core data collection combined observations with video recordings (459 minutes in Norway and 487 minutes in Portugal). This data were supplemented with ethnographic data, including audio recordings of post-interviews, pictures, student products, and extensive field notes. In keeping with our theoretical framework and research questions, the integration of the whole data corpus, including supplementary data, allowed for detailed descriptions of 
the settings, the framing of dialogue, and the interactions and activities across the different contexts (Paterson, Bottorff, \& Hewat, 2003).

In the analytical approach, we first used methods inspired by thematic analysis (Braun \& Clarke, 2006) to organize the data and to identify initial patterns of classroom interaction and dialogue within the data corpus (Ong-Flaherty et.al., 2017). These concerned how the two teachers organized the gameplay, and particularly how the gameplay was integrated with other activities and resources. This inductive process allowed us to work with identified patterns of interaction to develop a description of how the GBL trajectories unfolded over time. Second, we selected excerpts in which dialogue seemed to mediate learning related to the curriculum and to the five dilemmas presented by the game. The excerpts were first transcribed in their original languages and then translated into English (see transcription conventions in Appendix A). In keeping with research on established patterns of classroom talk (e.g. Alexander, 2006; Mercer \& Howe, 2012), we included both whole-class and small-group discussions. In the third phase of the analysis, we narrowed the focus and used micro-analytic approaches inspired by Jordan and Henderson (1995) to analyze dialogue and gameplay as an interactional accomplishment. This entailed analyzing utterances sequentially as "turns" through which the "inter-animation of different voices" (Bakhtin, 1981) allowed meanings to emerge and develop (Bakken \& Pierroux, 2015; Enqvist-Jensen, Nerland \& Rasmussen, 2017). The unit of analysis thus comprised moment-to-moment interactions embedded in class dialogues about ethics and moral reasoning, with the videogame as one of several contextual resources. In the fourth phase, we interpreted the data from the perspective of transformational play (Barab et al., 2010; 2012), extending principles for game design to the study of game-based learning in classroom settings. The analytical focus here was on the ways in which teachers enacted the positioning of person, content, and context to transform gameplay into learning experiences.

In sum, this framework allowed us to account for aspects of infrastructure, dialogical moves, and meaning making in the analysis. The two cases are complementary in the sense that they support and inform analyses and interpretations in relation to the themes in focus (Yin, 2010). In presenting the analysis of GBL, we identify what characterizes both differences and similarities, and we provide a rich description of how videogames and other classroom resources influence dialogic interactions and meaning making across the two contexts and between teachers.

\section{Analyzing Dialogic Interactions and the Use of a Videogame as Transformational Play}

\subsection{Infrastructure and organization of educational resources}

Different approaches to integrating the commercial videogame with other educational resources in classrooms were apparent in how the respective teachers organized activity sequences, or their 'enacted designs.' Specifically, the two teachers organized activities differently in terms of the sequence and integration of the videogame with 
concepts, tasks, and other resources. In the Portuguese case, the teacher presented all the ethical theories before introducing the videogame, using whole-class discussions and traditional resources (written handouts). The pace of gameplay was slower and the use of technology was limited to gameplay and voting using the Kahoot ${ }^{\mathrm{TM}}$ app. The Norwegian teacher instead opted for a very brief introduction, and used each of the game pauses to present a PowerPoint on the theory he believed best suited to that specific dilemma. The students then discussed possible game moves in small groups, having been instructed to use this theory as the main reasoning framework. After the small-group discussion, the students were invited to present their conclusions to the whole class. Then, using the digital app Geddit ${ }^{\mathrm{TM}}$, they individually voted to decide what should happen next in the game. Occasionally, during the theoretical explanations, students were asked to $\log$ in to Geddit ${ }^{\mathrm{TM}}$ and register their own comments and opinions, or to self-evaluate their theoretical understanding of the topic. The teacher in the Norwegian class used a tablet interface to alternate between the videogame and PowerPoint slides presented on an interactive whiteboard, while frequently calling on the students to use their personal laptops and smartphones to respond or comment on Geddit. ${ }^{\mathrm{TM}}$ In sum, analysis of the infrastructure, sequencing of tasks, and organization on educational resources identified the following activities in both settings:

- Gameplay: For long periods, the students collaborated on operating the controls while the game action was projected on a large screen.

- Theoretical explanations: Teachers provided theoretical explanations of curricular content to be integrated with the game activity.

- Discussion: Teachers organized instruction with discussion as a prime activity, pausing the game at key moral dilemma decision moments and leading students in discussions of possible actions.

- Voting: Following a period of discussion, students voted individually on what to do next in the game. The game action would then resume based on the majority decision on how to proceed. Voting entailed the use of digital apps, where students could select among possible options (formulated by the teachers to represent different theoretical positions).

Dialogues in the whole class and small group settings were also organized differently in the two cases. The two teachers used both closed and open approaches. Closed approaches refer to when students were instructed to consider only one ethical theory when discussing a dilemma, which was more frequently done in the Norwegian case. Open approaches refer to when students were invited to freely present arguments drawing on any or all the possible theories they had covered, which was more common in the Portuguese case. In the section below, we delve deeper into the empirical material to analyze what kind of positioning work, key to transformational play, was accomplished through the teachers' different instructional and dialogical approaches. We present an excerpt from the Portuguese case that illustrates 
'positioning person,' an example from the Norwegian case as 'positioning content,' and finally 'positioning context' is exemplified using excerpts from both cases. The excerpts were selected from the data corpus because they all involve discussions of ethics concepts, thus providing insight into how meaning making was supported in the different conditions.

\subsection{Positioning Person}

Transformational play requires players to position themselves in the role of protagonists who are able to make decisions in a fictional context (Barab et al., 2012). In The Walking Dead ${ }^{\mathrm{TM}}$, the players frequently assumed the identity of the main character. However, our analysis shows that the class discussions also contributed to person positioning because both students and teachers used the first person when referring to the characters' activities. The teachers in both cases frequently used the plural pronoun "we" to refer to the students' collaborative decision process: "What should we do here?" Such questions and person positioning were used to initiate debate, but also to scaffold group discussions. This agentive positioning engendered the use of hypothetical or actual examples from real life in discussions, as illustrated in the excerpt below.

In the videogame, Lee, the main character, and Clementine, the girl he is caring for, arrive at a farm and are seeking shelter. Hershel, the owner, has some doubts about letting them stay for the night. He starts asking troublesome questions about Lee's past, introducing a moral dilemma in which Lee must decide whether to tell the truth to Hershel. This dilemma is the first pause in the game. At this point, the Portuguese students had been playing the game for 45 minutes. The teacher invited the students to have an open whole-class discussion and to freely express their opinions about what should be done. This discussion lasted 18 minutes. Prior to the following excerpt, a student had just pointed out that lying is important for Lee to survive:

Excerpt 1: "Should we lie to Hershel?"

1 Teacher: So we lie ((shakes right shoulder slightly)) whenever we feel like it? Whenever it is convenient for us?!

2 Márcia: No! No, then ((moving body, gesticulating with hands))

((Some students stir, and there is talking at the same time. Ernesto is flipping through the handouts.))

3 Márcia: just in case of

4 Lucas: Teacher! For the greater happiness, teacher!

$5 \quad$ Teacher: Tell us, Lucas. ((Márcia leans forward, putting elbows on her knees. Some students look at Lucas and are silent.))

6 Lucas: In my opinion, I think it is it utilitarianism, because the action is by one person, but it is for a greater happiness, which is for his own good and Clementine's. ((waves arms wide open, first the left side, then the right side))

7 Teacher: For Clementine and for humanity. So is it justified to lie? 
Lucas: It is.

9 Teacher: So every time I feel like it, coming here ((open hands waving forward))

10 Márcia: No, no, Teacher! ((straightens right arm with open hand pointing towards the teacher.))

11 Teacher: And say "today we will have a test" ((back side of one hand beating the front of the other)) I'll get you all nervous; I'll put you all in panic.

12 Students ((overlapping talk among students))

13 Márcia: No! This is a matter of life or death! ((gesticulates and swings body back and forward))

14 Lucas: You, you must have some justification!

The teacher's invitation to students to make connections to theoretical concepts on their own reflects an open instructional approach. She also purposefully brought the game into the students' personal spheres by positioning them as protagonists, using first person pronouns to refer to the character in the game as "we" and "us"(line 1). Enacting a familiar, real-life scenario, the teacher-led dialogue shifted the students' position from 'players' to people who have an emotional investment in the moral dilemma, thus engaging them in passionate discussion. In fact, when expressing disagreement, students became visibly agitated, raising their voices, gesturing, and flipping papers (lines 2-3). This type of engagement is also characteristic of the discussions in this class. The students attempt to integrate other educational resources that have been provided by the teacher, seeking support for arguments in the handouts. Lucas managed to link the game to curriculum content by analyzing the character's actions in view of utilitarianism, an ethical theory described in the handout (lines 4 and 6). The teacher confirmed this interpretation as relevant, but questioned whether the argument could be extended to the general moral principle "it is justified to lie" (lines 7 and 8), further challenging the reasoning of the students by using her teaching practices as an example (lines 9 and 11).

From a meaning making perspective, the excerpt illustrates how a student masters a new concept by using it correctly in an argument, but also how the teacher's dialogical moves encourage the students to build on and appropriate ideas in ethics by relating them to an everyday social context. As discussion with the teacher playfully veers between conceptual talk and familiar situations, the young people are making ethics concepts 'their own' as they make their arguments (line 14).

\subsection{Positioning Content}

Positioning content entails relating domain-specific content to the game narrative to solve problems, to critically analyze the consequences of one's actions conceptually, and to develop a self-understanding as someone capable of solving real problems in this manner (Barab et al. 2012). The previous excerpt exemplified how narratives in games can be positioned as content through teacher-led dialogue, enabling students to 
understand how concepts and arguments in ethics can be usefully applied in other contexts.

In the game narrative, this time with the Norwegian students, the farmer Hershel allowed Lee and Clementine to spend the night on the farm. The next morning, zombies simultaneously attacked two other characters. One of them was a little boy named Duck and the other one was Shawn, the 20-year-old farmer's son. The game was paused when Lee needed to decide which one of them he would try to save. The teacher turned the game off the screen, put up a PowerPoint about the ethical theory of utilitarianism, and gave a five-minute theoretical explanation, presenting it as "an act that provides the most happiness." The students were then invited to discuss the dilemma in small groups, using utilitarianism as the starting point for their reasoning instead of the other theories already discussed.

After six minutes of small-group discussion, the teacher stopped the group activity and stood with his tablet at the front of the class to initiate a whole-class discussion, inviting the students to present their conclusions.

\section{Excerpt 2: "Should we save Duck or Shawn?"}

1 Teacher: OK then, I want to hear some arguments for and against. ((students stir)) Shhh...! Why save Duck? ((students slowly stop group work and turn to front $))$ Is there some argument for it, or against it, on this matter? ((Helge raises hand)) Helge?

2 Helge: That's the boy, right?

3 Teacher: Yes.

$4 \quad$ Helge: ((talks to the teacher who looks at him and says mm-mm at times. Class is silent)) In pure utilitarianism it is important to rescue the boy. I mean, he has the highest value happiness-wise. So like, if one actually saves the man, one could say that the man would get upset, because the boy was rescued (inaudible) that is, because purely ethically according to all possible norms I think that quite many would agree that this is most right. But at the same time, so you need to look into the situation, and the usefulness of the two persons. But since we are in such an early stage here, it is the boy who is most important to save. If, let's say, it had been ten years on or there had been in many situations like this, then I think the usefulness of the person (inaudible).

5 Teacher: Yes, good point. Are there others - or someone - who is for saving Shawn? Or against saving Shawn? ((looks around)) Sven?

6 Sven: We are for saving Shawn, so you get the most benefit from staying at his father's farm, and stuff like that, so we're trying to do the best for us to get the best later.

7 Teacher Yes, good point. Jens, to end.

8 Jens: But the way I understood it was that he, he got his foot run over, which of course drastically reduces his usefulness. 
The teacher applied a closed instructional design throughout, in the way in which the game was played and paused, in the tasks assigned to the small groups, and in the topic of class discussion afterwards. In the excerpt above, he invited the students to focus on one of the choices - to save the boy - and to present arguments either for or against this. Helge defended saving the child because he is the character with a "greater happiness value." His statement (line 4) is very close to the theoretical formulation about utilitarianism presented in the teacher's initial instruction ("an act that gives the most happiness"). His reasoning is quite advanced, as Helge uses theory to evaluate the value of each character, providing examples and concluding that the characters' value depends on the context. The student followed the instructional design by positioning content, a specific ethics concept, as a relevant tool for making game decisions. The teacher positively acknowledged this approach and continued inviting arguments (line 5). Sven, on behalf of his group, pointed to the direct benefits of saving the adult (line 6). At this point, Jens noted that, in the game, the adult character has had an accident that reduces his value to help to fight zombies (line 8). Implicit is the fact that a wounded character will present reduced utility to the group. The excerpt shows that the students' master the concept of utilitarianism, in that they can relate it to the game narrative and their reasoning in problem solving as characters in the game (line 6). The excerpt also illustrates the way in which the teacher's closed approach clearly frames their reflections, as they refer only to this specific concept and examples in the game to make a theoretically based argument.

\subsection{Positioning Context}

Positioning context describes how game environments are designed to contain a dramatic story that works as a situated scenario to contextualize learning (Barab et al. 2012). This context includes interactive mechanisms that enable the game's narrative structure to respond to players' actions in The Walking Dead' ${ }^{\mathrm{TM}}$, as well as the narrative content of navigating in a zombie apocalypse. In the excerpts below, we analyze the additional positioning work enacted by the teachers' respective instructional and dialogical approaches. Two excerpts are selected, one from each class, in which the students are asked to find a solution to dilemma number five. This dilemma occurs after Lee and his group leave the farm. They meet a woman who has been bitten by zombies. The lady is in a panic about becoming a zombie herself because she sees what is currently happening to her boyfriend who was in the same condition. She suddenly realizes that one person in Lee's group (Carley) has a gun, and desperately, she asks them to give her the gun, implicitly asking them to assist her in committing suicide. The game requires Lee to decide whether to give the woman the gun.

In the Portuguese setting, the teacher divided the class into three groups, and each group was assigned one theory. The task was to discuss possible solutions using the assigned theory and to write one argument for and one argument against giving the woman the gun. Arguments were then to be presented to the whole class. The excerpt is taken from an 11-minute small-group discussion among four students who chose to construct their arguments using the theory of psychological egoism. The 
teacher stood by the group. After seven minutes, Isabel had just finished writing down a discussed argument and begun reading it aloud to the working group: "We give her the gun so she can kill herself and her boyfriend so we do not have more to distract us, and we can continue on our way without worrying about whether we will be bitten or not." The conversation among some group members drifted off task before Ernesto returned their attention to the topic:

Excerpt 3: "Should we give the gun to the lady?"

1 Ernesto: But we're leaving.

2 Isabel: Yes.

3 Ernesto: And she stays there.

4 Teacher: So, we continue our journey.

5 Isabel Yes, we continue our journey.

6 Ernesto: What we can say is

7 Teacher: $\quad$ We get rid of her. ((Vânia looks up briefly to the teacher and back to Ernesto))

8 Ernesto: We continue on our way without remorse. ((Núria looks to Ernesto)) ((students laugh))

9 Isabel: Without remorse - that we can't do! ((pointing pen at Ernesto and laughing)) You gave her the gun...

10 Vânia Without... ((folds a tissue and raising her chin to Ernesto)) Without looking back!

11 Teacher: The egoist ... the egoist doesn't think of it, right?

12 Vânia: You just stay there, and off on your way! ((gesture of shooing forward, with her hand))

13 Isabel: ((looking at the written text on paper in her hand)) We are egoists; we do not think about it!

14 Teacher: Exactly.

15 Isabel: Come on now. Second argument ((resumes writing while Núria looks towards the sheet.))

16 Vânia: I'm very egoist today!

The students position context in several ways in this excerpt. First, they assume that the temporal structure of the narrative allows for the consideration of alternative action stages (we will leave, she will stay behind). After the students read the written formulation and Ernesto began to formulate an argument, the teacher abruptly interrupted him with the provocative declaration, "we get rid of her" (line 7). This break leads to a noticeable shift in the tone of the discussion, drawing the attention of the other students, apparent in their bodily orientations. Ernesto and Vânia picked up on the humorous sarcasm of the teacher's comment and playfully responded in kind (lines 8-10). Second, the students position context through appropriation, by 
reflecting on their own personal responsibility in alternative decision-making scenarios. Isabel remarked on the fact that a person providing a weapon for someone to commit suicide makes it impossible to avoid remorse (line 9). She used the second person and pointed to Ernesto with a pen while saying this. Positioning of context allowed them to extend their reasoning beyond the game to a real world context in which one's actions have consequence.

Now, the teacher had the students' attention and connected their reasoning to the theory (psychological egoism). Isabel looked down at the text they wrote as the teacher confirmed that they were on the right track (lines 12-14). The teacher's move of bringing theory into the dialogue is simultaneously orienting the students to the main task and to the conceptual domain. She positions the content in a way that contributes to this awareness, and toward a way of playing that is transformational for the students' mastering of the concept psychological egoism. The students showed some mastery of the concept as they picked up the teacher's first person enactments (line 13, "we don't think about it"), and they playfully appropriated the concept in informal speech related to the task at hand (line 16, "I'm very egoist today!").

In the Norwegian setting, after stopping the game, the teacher called this same dilemma "difficult." He compared it to the real-life problem of euthanasia. Linking the debate to the issue of euthanasia, the teacher connected theoretical content to broader societal issues, moving across contexts in the same way as the Portuguese teacher. He changed the screen to a PowerPoint and lectured for five minutes about duty ethics, the final ethical theory of the curriculum unit. The excerpt began as he ended his lecture and asked the students to talk together in groups, allowing the use of all the given theories: "Should one loan Carley's weapon to this lady or not? And why, then. Since we have now been through all of the different forms of ethics, you can use all four when discussing."

Excerpt 4: "Should we give the gun to the lady?"

1 Teacher: ((approaches the focal group)): OK. A particularly difficult dilemma. What should one do? ((Anders smiles at the teacher.))

2 Ola: Well. ((laughs slightly)) (.) Aahm, well...If you give... we think we should give her the gun and get away from her, or

3 Teacher: No, no, she will shoot herself in that case

$4 \quad$ Sven : So we take it back!

5 Ola: Yes, because if she would just... if you got away from there before she shot herself then technically you haven't seen it happening. ((swings arm towards table while speaking))

Approaching the group, the teacher restated the difficulty of the task and posed an open question (line 1) using an indefinite pronoun ("what should one do?" instead of "what should they do"). Ola picked up on this positioning when he responded by using the personal pronoun "you" as he began to make an argument, but shifted to "we," referring both to the characters and the students (line 2). Similar to the 
Portugese excerpt above, the teacher interrupted the student and pointed out the consequence of the chosen action (line 3). Sven quickly "takes back" the suggestion, showing how positioning consequentiality is dialogically mutable. Ola's reasoning in line 5 implies that the game context - its narrative structure - allows different scenarios to coexist, as an arena comprising personal unique points of observation as well as a backstage. We see that the teacher invited different opinions with an open instruction approach and used an additional instruction prompt, "And why," requesting the students to justify their decisions. Verbalizing issues of personal responsibility for actions is a way of dialogically positioning contexts as consequential. Also, the dialogue offers the possibility of 'taking back' a possible choice after reasoning about its consequences. This shows how positioning of the context is achieved, with consequentiality dialogically flexible. This excerpt illustrates students positioning contexts to adjust their dialogic reflections-in this case, the need to avoid facing responsibility for their actions.

The teacher followed up the issue of responsibility in relation to the consequences of the game context. He compared the present situation to the previous dilemma (excerpt 2), Shawn vs. Duck: "To what extent was Lee responsible for Shawn's fate, is it Lee's fault that Shawn died? (...) Is it Lee's fault now if he loans the gun to this lady, is it his fault that she dies? Is there a difference?" The students recognized a difference because in the first dilemma, Lee actually "did not put Shawn in the position that something could happen to him." Comparing the two dilemmas shows a dialogical approach in which positioning content is made possible by positioning context. In other words, the teacher draws on alternative narrative structures in the game (line 3) to prompt the students to reflect on whether there are conditions under which they might not have to deal with the problem of duty. The dialogue is used to discuss agency, consequentiality, and responsibility in a metareflective way. The main character is described as capable of providing means for $a$ particular consequence but, more, for being responsible or not for putting someone in a certain situation. Both consequences and moral implications of the character's actions (such as "fault") were discussed. This is a good example of how dialogue contributes to positioning context consequentially, resembling transformational play.

\section{Discussion}

In the presented excerpts, we analyzed the kind of positioning work - key to transformational play (Barab et al., 2010) - that was accomplished through the teachers' different instructional and dialogical approaches to GBL. In terms of positioning person, we found that teachers and students frequently assumed the role of protagonist and used the first person to refer to characters in the game ("But we are leaving," excerpt 1). We see the blurred distinction between players and characters ("we think we should give her the gun" excerpt 4) in the teachers' and the students' talk, which is quite common when people talk about videogames (Klimmt, Hefner, \& Vorderer, 2009). The agentive positioning engendered the use of both hypothetical and real-life experiences in the discussions. Role-playing was facilitated by the game's interactive potential, which allowed the player to choose actions and dialogue 
from programmed options. We found that the teachers' dialogical approaches played a central role in positioning students as 'change agents,' meaning that the students often displayed a sense of agency and ownership in the decisions they made, in their appropriation of the characters' dilemmas and in the solutions to these dilemmas (Wertsch, 1998). Positioning persons with intentionality ("So we lie whenever we feel like it?" excerpt 1) was accomplished through linking game dilemmas to real-life experiences. This allowed the students to engage in personal narratives that brought emotional resonance, linking learning with identity processes (Baranowski et al., 2008), and allowing students to appropriate elements of the narrative as their own through role-playing (Ryan et al., 2006). Such teacher-led talk, in both whole-class and small-group settings ("Have you ever been confronted with this situation?"), created an informal dialogical space that fostered spontaneity and student-student interactions.

Positioning person was closely linked with positioning content: inviting the students to use concepts from ethical theories to reason and make decisions positioned the students as informed and reflective protagonists. Examples come from both cases: in excerpt 1 in the Portugal case, Lucas refers to the act of Lee lying to the farmer in dilemma 1 as: "In my case, I think it is utilitarianism". Or in the Norwegian case, in dilemma 2, arguments for saving Duck over Shawn: "In pure utilitarianism it is important to rescue the boy." Using different instructions, the two teachers mediated the students' meaning making by relating their use of ethics concepts and theories to the situated gameplay experience. They wove contributions into coherent wholes (Alexander, 2006) and helped the students fill gaps between the confronted perspectives and an infinite number of possible new perspectives and insights (Bakhtin, 1981). Our analysis described how concepts became introduced and developed temporally through dialogue, as utterances were picked up and expanded on in an inter-animated, shared construction of meaning (Wegerif, 2011). Interchanging different instructional patterns led to a range of non-determined possible answers that were treated not as endpoints, but instead as generators of further questioning (Enqvist-Jensen et.al., 2016; Mercer, 2008).

The notion of positioning context was also expanded through game-related dialogues. An example of how virtual contexts are positioned with consequentiality through the dialogue itself is Lucas regretting the decision debated by his Portuguese colleagues regarding saving the adult instead of the child: "So now you will save the child, you will all die!". Lucas anticipates the consequences of the discussion. The idea that the game's dramatic story follows a responsive consequential system depending on the player's actions is intrinsic to the notion of transformational play. A good example is also when the student says "So we take it back" in excerpt 4. Existential issues are also dialogically positioned in relation to the game context: (if you get away from there before she shot herself then technically you haven't seen it happening). This implies that the game follows a course of its own, even without the characters' presence. The same co-existence of different scenarios within the game is expressed in excerpt 3, when Ernesto says "But we're leaving (...) and she stays there." Discussions in the two classes often predicted future game scenarios as though 
dependent on the choices made from their argumentation of ethical theories. Students engaged in passionate attempts to convince their peers to make certain choices, including personalizing examples and bringing in examples from real-life contexts, such as when the teacher referred to the hypothetical situation of a surprise test.

Finally, we noted variation in the way the videogame was integrated with other resources. In the Norwegian case, the extensive use of technological devices and platforms provided a sense of a tight or closed instructional structure and an accelerated class pace. The teacher integrated digital and non-digital traditional educational resources, such as printed handouts and PowerPoints, in the dilemmas of the game narrative. In the Portuguese case, the use of technology was limited to gameplay, and the teacher organized more time for more open and longer class discussions. However, although the two approaches created differences, they did not seem to have a direct effect on the interactional accomplishment of TP. This finding resonates with the idea that resources may be organized to exploit the pedagogical and interactional affordances of the videogame (Beauchamp \& Kennewell, 2010), aligned in a manner that preserves both the situated nature of the classroom and the fantasy aspects of the game narrative (Van Eck, 2009).

\section{Conclusion}

The similarities and differences in the two cases demonstrate what was vital for transformational play to occur. First, we found that several routes may be taken to accomplish the learning aims of transformational play. Teachers are different and so are classroom contexts both within and across countries. Both of the teachers integrated instruction, technology, and dialogue in gameplay activities, including theoretical explanations, class and group discussions, and voting. But the trajectories diverged in the two cases - one started by presenting theory 'up front' in the early lessons and using an open dialogical approach throughout, while the other incorporated concepts into tightly orchestrated dialogical spaces over time. Resources to support students in learning theoretical concepts included PowerPoints and printed handouts, and these were actively used and referred to during discussion activities in relation to the game narrative (Van Eck, 2009). Despite differences in instructional approaches, both facilitated students' understanding of ethical theories, suggesting that there are many ways for teachers to design GBL. In both cases, the teacher's dialogical approach was key to mediating relations between the theoretical content and game narrative, opening dialogic spaces for multiple perspectives and collaborative meaning making, and linking game dilemmas to identity issues and personal learning experiences (Silseth, 2012). Using questioning and justification more than aiming for correct answers was a common dialogical feature (Barab et al., 2010). We conclude that the potential of the commercial videogame as an educational resource was extended through teachers' instructional designs and dialogical approaches. Discussion and teacher interventions led to deeper and active learning through collaborative meaning making (Mercer, 2008), namely by discussions that prompted students to verbalize and connect knowledge (Wouters et al., 2013) 
Second, our analysis shows how different instructional and dialogical approaches allowed the teachers to accomplish positioning work, which is key to learning in transformational play. We verified that the use of instruction helped students to position person, content, and context as a useful resource for critical reasoning about ethical theories. We identified three types of positioning work that was dialogically accomplished in alignment with the videogame's affordances: (a) dialogues positioning the students as decision makers and investing them with authority and agency; (b) dialogues positioning the disciplinary content as a relevant resource for addressing ethical problems; and (c) dialogues positioning context in ways to reason about possible consequences that could be acknowledged and evaluated in productive ways. We conclude that the positioning work, accomplished with the teachers' different instructional and dialogical approaches to game-based learning, was key to transformational play. Also relevant is Gee's (2003) point that videogames invite learners to relate to, navigate and reflect on different roles and identities, which in this case was far from the students' everyday. The gameplay nevertheless seemed to bridge the students' real experiences and the presented theories and supported them in reasoning about moral and ethical issues through the narrative structure and content of the game, but more importantly through the teachers' organization and enacted learning design. The findings have implications for the design of learning situations that integrate new technologies with more traditional approaches, and are in line with accumulating evidence of the value of discussion and how teachers should facilitate students learning with technology. Principles for productive learning, such as TP, may support students' learning when programmed into serious games (Barab et al. 2012), but our study suggests that learning is also facilitated when teachers' enacted designs for game-based learning follow these principles. Teachers plan a learning environment with educational resources and instructional designs, but may be unsure about the use and assessment of new resources such as videogames. We propose that TP can function as a framework and a guide for planning and evaluating lessons with videogames. This study shows that commercial games may function as a productive resource for learning in formal education, and can create opportunities to engage students in learning experiences that bridge in-school and out-of-school practices. Further studies may extend these findings to other videogames and learning designs, to investigate issues related to transfer and possible applications in other disciplinary domains.

\section{References}

Advisory Group on Citizenship. (1998). Education for Citizenship and the Teaching of Democracy in Schools. London: Qualifications and Curriculum Authority. Accessed 24 October 2014. http://dera.ioe.ac.uk/4385/1/crickreport1998.pdf

Alexander, R. J. (2006). Towards Dialogic Teaching: Rethinking Classroom Talk. 3rd ed. Cambridge: Dialogos.

Arici, A. D. (2008). "Meeting Kids at Their Own Game: A Comparison of Learning and Engagement in Traditional and Three-dimensional MUVE Educationalgaming contexts." PhD diss., Department of Psychological and Brain Sciences, 
Indiana University.

Bakhtin, M. (1981). The Dialogic Imagination: Four Essays. ed. Michael Holquist and Caryl Emerson. Austin: University of Texas Press.

Bakken, S. M., \& Pierroux, P. (2015). Framing a topic: Mobile video tasks in museum learning. Learning, Culture and Social Interaction, 5, 54-65.

Barab, S., Gressalfi, M. \& Arici A. (2009). "Why Educators Should Care About Games." ASCD: Educational Leadership 67(1): 76-80.

Barab, S., Gresalfi, M. \& Ingram-Goble, A. (2010). "Transformational Play: Using Games to Position Person, Content, and Context." Educational Researcher 39 (7): 525-536.

Barab, S., Pettyjohn P., Gresalfi, M., Volk, C. \& Solomou, M. (2012). "Game-Based Curriculum and Transformational Play: Designing to Meaningfully Positioning Person, Content, and Context." Computers \& Education 58 (1): 518-533.

Barab, S., Sadler, T., Heiselt, C., Hickey, D., \& Zuiker, S. (2010). "Erratum to: Relating Narrative, Inquiry, and Inscriptions: Supporting Consequential Play." Journal of Science Education and Technology 19 (4): 387-407.

Baranowski, T., Buday, R., Thompson, D. I. \& Baranowski, J. (2008). "Playing for Real: Video Games and Stories for Health-Related Behavior Change." American Journal of Preventive Medicine 34 (1): 74-82.

Beauchamp, G. \& Kennewell, S. (2010). "Interactivity in the Classroom and its Impact on Learning." Computers \& Education 54 (3): 759-766.

Braun, V., \& Clarke. V. (2006). "Using Thematic Analysis in Psychology." Qualitative Research in Psychology 3 (2): 77-101.

de Freitas, S. I. (2006). "Using Games and Simulations for Supporting Learning." Learning, Media, and Technology 31 (4): 343-358.

Edmiston, B. (2008). Forming Ethical Identities in Early Childhood Play. Oxon: Routhledge.

Enqvist-Jensen, C. Nerland, M. \& Rasmussen, I. (2017). Maintaining doubt to keep problems open for exploration: An analysis of law students' collaborative work with case assignments. Learning, Culture and Social Interaction. ISSN 2210-6561. doi: http://dx.doi.org/10.1016/j.lcsi.2017.02.001

Erstad, O. (2013). Digital Learning Lives: Trajectories, Literacies, and Schooling. New York: Peter Lang.

Gee, J. P. (2003). What Video Games Have to Teach Us about Learning and Literacy. United Kingdom: Palgrave Macmillan Ltd.

Gresalfi, M., \& Barab, S. (2011). "Learning for a Reason: Supporting Forms of Engagement by Designing Tasks and Orchestrating Environments." Theory Into Practice 50 (4): 300-310.

Gresalfi, M., Barab, S., Siyahhan, S., \& Christensen, T. (2009). "Virtual Worlds, Conceptual Understanding, and Me: Designing for Consequential Engagement." On the Horizon 17 (1): 21-34.

Gilje, Ø., Ingulfsen L., Dolonen, J.A., Furberg, A., Rasmussen, I., Kluge A., Knain, E., Mørch, A., Naalsund, M. \& Granumj K. (2016). Bruk av Laeremidler og Ressurser for Laring på Tvers av Arbeidsformer. [The use of Teaching Tools and Resources for Learning Across Teaching Methods] Ark\&App Report. Oslo: University of Oslo. https://www.uv.uio.no/iped/forskning/prosjekter/arkapp/arkapp_syntese_endelig_til_trykk.pdf 
Hanghøj, T. (2013). “Game-based Teaching: Practices, Roles, and Pedagogies”. In New Pedagogical Approaches in Game Enhanced Learning: Curriculum Integration, edited by S. de Freitas, M. Otta, M. M. Popescu, and I. Stanescu, 81-101. Hershey PA: IGI Global.

Hanghøj, T., \& Brund, C. E. (2010). Teacher Roles and Positionings in relation to Educational Games. In Proceedings of the 4th European Conference on Games Based Learning, edited by B. Meyer, 115-122. Reading: Academic Conferences Limited.

Haydn, T. (2012). "ICT and Citizenship Education." In Debates in Citizenship Education, edited by James Arthur and Hilary Cremin, 169-178. London: Routledge.

Hontvedt, M. (2015). "Professional vision in simulated environments - Examining professional maritime pilots' performance of work tasks in a full-mission ship simulator" Learning, Culture and Social Interaction 7: 71-84.

Hull, Glynda, and Katherine Schultz. 2001. "Literacy and Learning Out of School: A Review of Theory and Research." Review of Educational Research 71 (4): 575-611.

Jahreie, C. F., Arnseth, H.C., Krange, K., Smørdal, O. \& Kluge, K. (2011). "Designing for Play-based Learning of Scientific Concepts: Digital Tools for Bridging School and Science Museum Contexts." Children, Youth and Environments, 21 (2): 236-255.

Jordan, B. \& Henderson, A. (1995). "Interaction Analysis: Foundations and Practice." The Journal of the Learning Sciences 4 (1): 39-103.

Klimmt, C., Hefner, D. \& Vorderer, P. (2009). "The Video Game Experience as 'True' Identification: A Theory of Enjoyable Alterations of Players' Self-Perception." Communication Theory 19 (4): 351-373.

Kriz, W. C. (2010). "A Systemic-Constructivist Approach to the Facilitation and Debriefing of Simulations and Games". Simulation \& Gaming 41 (5): 663-680.

Linderoth, J. (2012). "Why gamers don't learn more: An ecological approach to games as learning environments." Journal of Gaming and Virtual Worlds 4 (1).

Marino, M. T. \& Hayes, M. T. (2012). "Promoting Inclusive Education, Civic Scientific Literacy, and Global Citizenship with Videogames." Cultural Studies of Science Education 7 (4): 945-954.

Mercer, N. (2008). "Talk and the Development of Reasoning and Understanding." Human Development 51 (1): 90-100.

Mercer, N., \& Howe, C. (2012). Explaining the dialogic processes of teaching and learning: The value and potential of sociocultural theory. Learning, Culture and Social Interaction, 1(1), 12-21. doi:http://dx.doi.org/10.1016/j.lcsi.2012.03.001

Norwegian Ministry of Education. (2015). "Curriculum for Knowledge of Christianity, Religion, Philosophies of Life and Ethics (RLEL-02)." Norwegian Ministry of Education. Accessed 2 January 2014. https://www.udir.no/k106/RLE102?lplang=eng

Portuguese Ministry of Education. (2004). "Programa componente de formação sociocultural: Disciplina de area de integração. [Component Program of Socio-Cultural Training: Discipline of Integration Area].” Portuguese Ministry of Education. Accessed 4 January 2013. http://www.catalogo.anqep.gov.pt/programascp/CP_FSC_Area_Integracao.pdf

O'Connor, C., Michaels, S. (2007). "When is Dialogue 'Dialogic'?" Human Sevelopment 50 (5): 275-285. 
Ong-Flaherty, C., Valencia- Garcia, D., Martinez, D.A., Borges, W., \& Summers, L. (2017). "Effectiveness of gaming in creating cultural awareness." Learning, Culture and Social Interaction, 12: 149-158. doi: 10.1016/j.lcsi.2016.12.005

Paterson, B. L., Bottorff, J. L. \& Hewat, R. (2003). "Blending Observational Methods: Possibilities, Stategies, and Challenges." International Journal of Qualitative

Pierroux, P. (2010). Guiding Meaning on Guided Tours. Narratives of Art and Learning in Museums In A. Morrison (Ed.), Inside Multimodal Composition (pp. 417-450). Cresskill, NJ: Hampton Press.

Rasmussen, I. \& Ludvigsen, S.L. (2010). "Learning with Computer Tools and Environments: A Sociocultural Perspective.” In International Handbook of Psychology in Education, edited by Karen Littleton, Clare Wood, and Judith Kleine Staarman, 399-433. Bingley: Emerald Group Publishing Limited.

Ryan, Richard M., C. Scott Rigby, and Andrew Przybylski. 2006. "The Motivational Pull of Video Games: A Self-Determination Theory Approach." Motivation and Emotion 30 (4): 344-360.

Sanchez, E. (2013). "A Model for the Design of Digital Epistemic Games.” Paper presented at the Proceedings of the X World Conference on Computers in Education, Torun, Poland, July 1-7, 2013: 257-264.

Schuitema, J., van Boxtel, C., Veugelers, W \& ten Dam, G. (2011). "The Quality of Student Dialogue in Citizenship Education." European Journal of Psychology of Education 26 (1): 85-107.

Sellberg, C., \& Lundin, M. (2017). Demonstrating professional intersubjectivity: The instructor's work in simulator-based learning environments. Learning, Culture and Social Interaction 13: 60-74.

Silseth, K. (2012). "The multivoicedness of Game Play: Exploring the Unfolding of a Student's Learning Trajectory in a Gaming Context at School." International Journal of Computer-Supported Collaborative Learning 7 (1): 63-84.

Squire, Kurt. (2005). "Changing the Game: What Happens when Video Games Enter the Classroom?" Innovate: Journal of Online Education 1 (6). n.p.

Selwyn, N. (2016). "Minding our language: why education and technology is full of bullshit ... and what might be done about it." Learning, Media and Technology 41 (3): 437-443

Telltale Games. (2012). “A New Day” In The Walking Dead" Season 1. San Rafael: Skybound Entertainment.

Van Eck, R. (2009). "A Guide to Integrating COTS Games into Your Classroom." In Handbook of Research on Effective Electronic Gaming in Education, edited by Richard E. Ferdig, 179-199. Hershey: Idea Group.

Vestøl, J. M. (2004). "Relasjon og Norm i Etikkdidaktikken: Moralsk/Etisk Verktøybruk i Spennet Mellom Elevtekster og Fagdidaktiske Framstillinger. [Relation and Norm in Moral Education: Rhe Use of Moral / Ethical Tools in the Range Between Student Texts and Didactic Presentations]." PhD diss., University of Oslo.

Wegerif, R. (2011). Towards a dialogic theory of how children learn to think.

Thinking Skills and Creativity 6 (3): 179-190

Wells, G. (2007). "Semiotic Mediation, Dialogue and the Construction of Knowledge." Human Development 50 (5): 244-274.

Wertsch, J. V. (1998). Mind as Action. New York: Oxford University Press.

Willems, F., Denessen, E., Hermans, C., \& Vermeer, P. (2013). "Assessing Qualities of Moral Classroom Conversations in the Domain of Citizenship Education: A 
Virtue Ethical Approach." Journal of Research in Character Education 9

(2):107-119.

Wouters, P., Van Nimwegen, C., Van Oostendorp, H., \& Van Der Spek, E. D. (2013).

"A Meta-Analysis of the Cognitive and Motivational Effects of Serious

Games." Journal of Educational Psychology 105 (2): 249-265. 